\title{
LXXVIII. On a new and expeditious method of naming at sight the roots of complete cubes under ten figures
}

John Evans Jun. A.M.

To cite this article: John Evans Jun. A.M. (1818) LXXVIII. On a new and expeditious method of naming at sight the roots of complete cubes under ten figures, Philosophical Magazine Series 1, 51:242, 443-444, DOI: $10.1080 / 14786441808637586$

To link to this article: http://dx.doi.org/10.1080/14786441808637586

电 Published online: 27 Jul 2009.

Submit your article to this journal $₫$

Џll Article views: 2

Q View related articles $\sqsubset$ 


\section{[ 443 ]}

LXXVIII. On a new and expeditious Method of naming at sight the Roots of complete Cules under Ten Fignres. By John Evans Jun. A.M.

SIR, - IN a former volume of your valuable Miscellany, I recollect having met with some communications, in which is given a method of naming at sight the root of any complete cube number under seven figures. The principle was briefly this :-The root will evidently not exceed two figures; - - of which the first, or digit of tens, will be the root of the greatest cube contained in the 4 th, 5 th, and 6 th figures of the given number, counting from the right hand:-and the latter, or terminating figure of the root, will be found by considering that if the cube terminate in $1,4,5,6$, or 9 , the root will terminate in the same figure; if in $2,3,7$, or 8 , the termination of the root will be $8,7,3$, or 2 , the respective deficiencies from 10 .

Now, sir, it has occurred to me, that by uniting another principle with the method just alluded to, we may name at sight, if required, the root of any cube number not exceeding nine figures. This is effected by the following rules :

1. It is obvious that the required root will never exceed three figures:- the first of which will be the root of the greatest cube contained in the $7 \mathrm{th}, 8 \mathrm{th}$, and 9 th figures counting from the right.

2. The terminating figure of the root may be found as before from the termination of the given cube.

3 . To obtain the middle figure of the root, divide the given cube by 11 , and according as the remainder is,

$$
\begin{gathered}
0,1,2,3,4,5,6,7,8,9 \text {, or } 10 \\
\text { take } 0,1,7,9,5,3,8,6,2,4 \text {, or } 10
\end{gathered}
$$

which being subtracted from the sum of the first and last figures (found as above) borrowing 11 , if necessary, will give the middle figure of the root.

Take as an example tHE COMPLETE CUBE 504358336 .

1. The greatest cube in 504, the $7 \mathrm{th}, 8 \mathrm{th}$, and 9 th figures, is 343 , or $(7)^{3}$ : therefore the first figure of the root is 7 .

2 . Since the cube ends in 6 , the termination of the ront is 6 .

3 . Dividing the given cube by 11 , the remainder is 9 , to which 4 corresponds in the series given above. Then the two former figures 7 and 6 added together give 13, from which 4 being deducted, leaves 9 for the middle figure of the root. Hence the root required is 796 .

Again, let the proposed cube be 6028568 .

1. The root of the greatest cube in 6 is 1 .

2. The termination will be $10-8=2$. 


\section{Nethod of naming Roots of Cules under Ten Figures.}

3. The remainder, after dividing by 11 , is 7 , whose corresponding number 6 being subtracted from $2+1+11$, or $1 !$, leaves 8 for the middie figure of the root, which is therefore $18 \%$.

The principles on which are founded the rules for obtaining the first and last figures of the root, are perhaps sufficiently evident. The rule, however, for the midale figure, on which alone I rest my claim for originality in the present instance, depends upon the following obvious property. If a given number divided by 11 leave a certain remainder $r$, and the cube of $r$ be divided by 11 , the new remainder $r^{\prime}$ left after this second division will he the same as what would remain, if the cube of the original number were divided by 11 ; and further, if $r$ be $0,1,2,3,4,5,6,7,8,9$, or 10 , it will be found upon trial that $r^{\prime}$ will be $0,1,8,5,9,4,7,2,6,3$, or 10 : or inversely, if $r^{\prime}$ be $0,1,2,3,4,5,6,7,8,9$, or $10, r$ will be $0,1,7,9$, $5,3,8,6,2,4$, or 10 . Consequently since $r^{\prime}$ is obtained by dividing the proposed cube by $11, r$ may be found by the series; i.e. the remainder that should result from the division of the root by 11 . But it is well known that if the remainler arising from casting the elevens out of the enen digits of any given number, be subtracted from the remainder arising from casting the elevens ont of the odd digits, the resulting remainder is what would remain, if the given number were divided by 11 . Hence if $r$ be subtracted from the sum of the first and last figures already found, borrowing 11 , if necessary, it is obvious that the difference will be the iniddle figure of the rout.

If, sir, the method I have just described, which is, to the best of my knowledge, entirely new as respects its extension to cubes above six figurss, and which certainly far surpasses the common method in conciseness and facility of arplication, be decmed by rou worthy of a place in your Magazine, your insertion of it will oblige yours, 8c.

Islington, June 16, 1818.

JoHn Evans Jun.

P.S.-Before I conclude this communication, allow me just to hint, that in the rule 1 have suggested, the method of casting out clevens may be sometimes conveniently substituted for the division by 11 .

It mav likewise not be improper to remark that the series $0,1,7,9,5,3,8,6,2,4,10$, may be easily and firmly fixed in the memory, by observing that if we omit the 0 , the sun of any two terns equally distant from the extremes is always 11 ; thus $1+10=7+4 \& \mathrm{c} .=11$ : also that the first five consist of all the odd numbers, the last five of all the even numbers under 11: and lastly, that the differences of the series are in the following regular urder, $6,2,-4,-2,5,-2,-4,2,6$. 